\title{
ANALISIS PERENCANAAN KAPASITAS PRODUKSI DENGAN METODE ROUGHT CUT CAPACITY PLANNING (RCCP) PADA PEMBUATAN PRODUK KASUR BUSA (Studi pada PT Buana Spring Foam di Purwokerto)
}

\author{
Akrimi Matswaya*1, Bambang Sunarko², Retno Widuri' ${ }^{3}$, Suci Indriati ${ }^{4}$ \\ 1,2,3,4 Jurusan Manajemen, Fakultas Ekonomi dan Bisnis, Universitas Jenderal Soedirman, Indonesia \\ *Email corresponding author: akrimi376@gmail.com
}

\begin{abstract}
Abstrak
Penelitian dilakukan pada PT Buana Spring Foam di Purwokerto, yang memproduksi spring bed dan kasur busa. Pokok masalah dalam penelitian ini adalah menyusun rencana kapasitas produksi kasur busa sehingga mampu memenuhi permintaan konsumen yang beragam sesuai dengan yang dijadwalkan. Perencanaan kapasitas dilakukan dengan metode Rought Cup Capacity Planning (RCCP) yang memiliki empat langkah yang harus dilakukan. Pertama, melakukan peramalan dengan metode trend, metode pemulusan dengan musiman, metode moving average, dan metode pemulusan. Kemudian menghitung perencanaan agregat dengan metode tenaga kerja tetap dan metode transportasi atas dasar hasil peramalan. Selanjutnya dilakukan proses disagregasi dengan metode cut \& fit. Kedua, menentukan waktu proses produksi. Ketiga, menghitung bill of capacity dengan cara mencari standar hours pada setiap jenis produk. Keempat, menghitung kebutuhan sumber daya spesifik dan membuat laporan RCCP. Sedangkan untuk kapasitas tersedia didapat dari perhitungan rencana produksi. Bedasarkan hasil perhitungan tersebut dibuat load profile yang menunjukan bahwa hasil penelitian terhadap jadwal induk produksi layak digunakan untuk proses produksi kasur busa. Kelayakan ini dihitung berdasarkan kesesuaian antara total kapasitas tersedia 28224 unit dengan kapasitas terpakai 19415 unit. Oleh karena itu kapasitas tersedia dapat memenuhi kapasitas terpakai. Kata Kunci: Kapasitas Produksi, Jadwal Induk Produksi, Rought Cut Capacity Planning
\end{abstract}

\begin{abstract}
The research was conducted at PT Buana Spring Foam in Purwokerto, which produces spring beds and foam mattresses. The main problem in this study is to develop a plan for the production so they are able to meet various consumer demands according to the schedule. Capacity planning is conducted by the Rought Cup Capacity Planning (RCCP) method which has steps. First, forecasting using trend methods, smoothing methods with seasonality, moving average methods, and smoothing methods. Then calculate the aggregate planning with permanent labor and transportation methods on the basis of forecasting results. The disaggregation process is then carried out using the cut \& fit method. Second, determine the production process time. Third, calculate the bill of capacity by finding the standard hours for each type of product. Fourth, calculate specific resource requirements and make an RCCP report. Whereas the available capacity is obtained from the calculation of the production plan. Based on the results of the calculation, a load profile is made that shows that the results of research on the master production schedule are suitable for the production of foam mattresses. This feasibility is calculated based on the compatibility between the total available capacity of 28224 units and the utilization capacity of 19415 units. Therefore, the available capacity can meet the used capacity.
\end{abstract}

Keywords: Production Capacity, Master Production Schedule, Rought Cut Capacity Planning

\section{PENDAHULUAN}

PT Buana Spring Foam adalah unit perusahaan dari Cahaya Buana Group, lokasi PT Buana Spring Foam di Jl. Veteran No.234, Dusun I, Pangebatan, Karanglewas, Kabupaten Banyumas, Jawa Tengah 53161. Perusahaan ini begerak dalam bidang perdagangan dan industri manufaktur. PT Buana Spring Foam memproduksi spring bed dan kasur busa. Namun, penelitian ini berfokus pada produksi kasur busa, sehingga jangkauan penelitiannya tidak terlalu luas. Produk kasur busa memiliki empat jenis produk, yaitu gold, silver, standar dan ekonomi. Pada proses produksi kasur busa terdapat kendala pada

\footnotetext{
${ }^{1}$ Mahasiswa

${ }^{2}$ Desen Pembimbing

${ }^{3}$ Dosen Pembimbing

${ }^{4}$ Dosen Penguji Skripsi
} 
saat adanya permintaan khusus dan musim-musim tertentu. Mutu, waktu, dan biaya dianggap sebagai tiga faktor kritis dari beberapa faktor yang mempengaruhi kepuasan pelanggan karena umumnya pelanggan menilai perusahaan dalam ketiga faktor tersebut. Perusahaan akan mampu memberikan nilai terbaik kepada pelanggannya apabila memiliki rencana produksi yang realistis yang berarti bahwa output produksi direncanakan berdasarkan sumber daya potensial, khususnya kapasitas produksi.

Permintaan konsumen dapat terealisasi seluruhnya di dalam jadwal induk produksi jika didukung oleh kapasitas produksi yang sesuai dengan kebutuhan produksi di dalam menghasilkan persediaan produk jadi. Jadwal induk produksi dapat dengan mudah direalisasikan apabila permintaan konsumen bersifat konstan, namun kenyataannya perusahaan tak jarang mengalami fluktuasi permintaan yang cenderung menurun dan tidak stabil. Dari hasil jadwal induk produksi pada PT Buana Spring Foam, maka akan diuji dengan metode Rought Cut Capacity Planning, sehingga perusahaan mengetahui apakah sumber daya yang direncanakan akan cukup atau bahkan kelebihan. Data yang digunakan adalah data penjualan pada bulan Januari 2017 sampai bulan Desember 2018 dan kebijakan-kebijakan perusahaan lainnya.

\section{TINJAUAN PUSTAKA \\ Peramalan}

Sistem peramalan menggunakan berbagai model peramalan, hal ini akan memberikan nilai ramalan yang berbeda pada setiap perhitungannya. Salah satu seni dalam melakukan peramalan adalah memilih model atau teknik ramalan yang terbaik. Model ramalan yang terbaik adalah model ramalan yang mampu mengidentifikasi dan menanggapi pola aktivitas histori dari data. Secara umum, modelmodel peramalan menurut Gaspersz (1998:85) dapat dikelompokan kedalam dua kelompok utama, yaitu metode kualilatif dan metode kuantitatif. Selanjutnya metode kuantitatif dikelompokan kedalam dua bagian utama, yaitu intrinsik dan ekstrinsik. Model kualitatif ditunjukan untuk peramalan terhadap produk baru, proses baru, pasar baru, perubahan teknologi, perubahan sosial dari masyarakat, atau penyesuaian terhadap ramalan-ramalan berdasarkan metode kuantitatif. Model kuantitatif intrinsik sering disebut dengan model deret waktu.

Ada tiga ukuran yang digunakan untuk menghitung kesalahan historis, yaitu Mean Absolute Deviation (MAD) adalah rata-rata kesalahan absolut, Mean Squared Error (MES) adalah rata-rata kesalahan kuadrat ramalan, dan Mean Absolute Percent Error (MAPE) adalah rata-rata persentase kesalahan absolut.

\section{Kapasitas Produksi}

Kapasitas merupakan suatu terobosan atau sejumlah unit yang terdapat tempat fasilitas menyimpan, menerima atau memproduksi dalam suatu periode waktu tertentu (Heizer dan Render, 2016:348). Menurut Blackstone 1989 (dalam Jurnal Inovasi Vol. 6, No. 2, Oktober 2007:141) kapasitas merupakan sebagai jumlah output maksimum yang dapat dihasilkan suatu fasilitas produksi dalam selang waktu tertentu. Kapasitas berfokus pada batas atas atau beban maksimum yang bisa dilakukan oleh unit produksi. Beban itu dapat berupa jumlah jasa yang dilakukan dan jumlah unit fisik yang dihasilkan. Kusuma (2009:113) berpendapat bahwa pengertian kapasitas ini harus dilihat dari tiga perspektif agar lebih jelas, yaitu: kapasitas desain, kapasitas efektif, dan kapasitas aktual.

\section{Perencanaan Agregat}

Heizer dan Render (2016:607) berpendapat bahwa rencana agregat adalah suatu rencana yang menyertakan tingkat ramalan untuk kelompok produk barang jadi, persediaan, kekurangan, dan perubahan tenaga kerja. Perencanaan agregat penting karena dapat membantu menyelaraskan aliran di sepanjang rantai pasokan; perencanaan ini mempengaruhi biaya, penggunaan perlengkapan, tingkat pekerjaan dan kepuasan pelanggan 
Kusuma (2009:62) berpendapat bahwa ada empat metode dalam menghitung perencanaan agregat yang sesuai dengan kondisi perusahaan, yaitu: metode koefisien bowman, metode program linier, metode parametik jones, dan metode transportasi.

\section{Proses Disagregasi}

Disagregasi adalah proses memecah rencana agregat menjadi kebutuhan produk spesifik dengan tujuan untuk menentukan kebutuhan tenaga kerja, material, dan kebutuhan persediaan (Stevenson dan Chuong, 2014:270). Sedangkan menurut Kusuma (2009:81) proses disagregasi bertujuan untuk membuat jadwal produksi secara terperinci pada setiap item produk.

Pada proses disagregasi ini dapat dibagi menjadi empat metode, diantaranya (Girsang et al., 2016:13): (1) metode Cut \& Fit merupakan metode ini sering digunakan dalam suatu perusahaan untuk mengupayakan mencari berbagai variasi alokasi kapasitas produksi pada suatu grup sampai tercapai kombinasi yang terbaik, (2) metode Hax \& Britan ada beberapa langkah dalam menentukan metode ini, yakni menentukan family yang diproduksi, disagregasi family, disagregasi item, dan menentukan status inventori akhir dari setiap produk, (3) metode Hax \& Meal, metode ini bertujuan untuk menentukan jumlah produksi berdasarkan dari trade-off biaya simpan dengan biaya setup pesan, (4) metode Linier Progamming, metode ini berupa program linier yang bertujuan untuk meminimalkan biaya total dari output, subkontrak, inventori, backlog, hiring, layout, overtime, dan gaji untuk n periode.

\section{Jadwal Induk Produksi}

Jadwal induk produksi merupakan rencana rinci tentang jumlah barang yang akan diproduksi pada beberapa satuan waktu dalam horison perencanaan (Kusuma, 2009:173). Sedangkan menutur Heizer dan Render (2016:642) menyatakan jadwal induk produksi menetapkan apa yang harus dihasilkan dan waktu yang telah ditetapkan sesuai dengan keseluruhan rencana.

Jadwal induk produksi adalah suatu pernyataan tentang produk akhir atau item apa yang direncanakan untuk diproduksi, berapa banyak produk atau item tersebut akan diproduksi pada setiap periode sepanjang rentang waktu perencanaan. Rencana induk produksi berfungsi sebagai basis dalam penentuan jadwal proses operasi di lantai pabrik, jadwal pengadaan bahan dari luar perusahaan (boughout materials) dan jadwal alokasi sumber daya untuk mendukung jadwal pengiriman produk kepada pelanggan.

\section{Rought Cut Capacity Planning}

Menurut Sinulingga (2009:130) Rough Cut Capacity Planning (RCCP) adalah suatu proses analisis dan evaluasi kapasitas dari fasilitas produksi yang tersedia di lantai pabrik agar sesuai atau dapat mendukung jadwal induk produksi yang akan disusun. Ada empat teknik untuk mengitung Rough Cut Capacity Planning, yaitu: CPOF (Capacity Planning Overall Factor), BOLA (Bill Of Labour Approach), RPA (Resource Profile Approach), dan CRP (Capacity Requirement Planning).

\section{METODE PENELITIAN}

Jenis penelitian ini merupakan penelitian studi kasus dengan menggunakan metode survei yang bertujuan untuk mengumpulkan informasi dan data-data yang dibutuhkan untuk menghitung kapasitas produksi agar memenuhi jumlah permintaan yang optimal dan tentunya dapat diselesaikan secara tepat waktu. Penelitian ini dilaksanakan pada perusahaan PT Buana Spring Foam.

Jenis data dalam penelitian ini ada dua, yaitu data kualitatif dan data kuantitatif. Data kualitatif diperoleh dari hasil wawancara dengan manajer perusahaan dan karyawan PT Buana Spring Foam serta informasi-informasi yang diperoleh dari pihak lain yang berkaitan dengan masalah yang diteliti. Sedangkan data kuantitatif diperoleh dari pengamatan langsung yang bersifat data primer yaitu data tentang proses produksi, waktu proses produksi pada setiap mesin, dan biaya-biaya mengenai kebijakan perusahaan. 
Teknik pengumpulan data dalam penelitian ini menggunakan tiga cara, yaitu observasi, wawancara, dan dokumentasi. Observasi (observation) yaitu teknik pengumpulan data dengan mengamati secara langsung terhadap aktivitas karyawan dalam melakukan tugasnya, wawancara (interview) merupakan teknik pengumpulan data dengan cara mengadakan tanya jawab dengan manajer perusahaan dan karyawan PT Buana Spring Foam yang bersangkutan dengan permasalahan penelitian, sedangkan dokumentasi (documentation) yaitu teknik pengumpulan data dengan cara meminta catetan atau informasi perusahaan yang terdahulu.

Penelitian ini dilakukan dengan menerapkan metode Rought Cut Capacity Planning (RCCP) yang memiliki empat langkah dasar: (1) menentukan rencana produksi dan Jadwal Induk Produksi, (2) menentukan standar waktu pada setiap stasiun kerja, (3) menentukan Bill of Capacity, (4) menyusun laporan Rought Cut Capacity Planning (RCCP).

\section{HASIL PENELITIAN DAN PEMBAHASAN}

\section{Data Perusahaan}

Untuk memudahkan dalam melakukan penelitian ini, maka dapat dilihat data penjualan kasur busa periode Januari 2017 sampai dengan Desember 2018, sebagai berikut:

Tabel 1 Penjualan Kasur Busa Tahun 2017

\begin{tabular}{rlrrrrr}
\hline Tahun & Bulan & Periode & Gold (unit) & Silver (unit) & Standar (unit) & Ekonomi (unit) \\
\hline \multirow{6}{*}{2017} & 1 & 21 & 239 & 35 & 1325 \\
& Januari & 10 & 146 & 18 & 1129 \\
& Maruari & 2 & 12 & 284 & 61 & 1493 \\
& April & 4 & 18 & 186 & 0 & 1685 \\
& Mei & 5 & 5 & 224 & 32 & 1476 \\
Juni & 6 & 8 & 182 & 24 & 2136 \\
& Juli & 7 & 4 & 166 & 52 & 2612 \\
& Agustus & 8 & 8 & 133 & 5 & 2353 \\
& September & 9 & 1 & 89 & 78 & 1230 \\
& Oktober & 10 & 19 & 153 & 2 & 948 \\
& November & 11 & 12 & 121 & 75 & 780 \\
Desember & 12 & 15 & 102 & 1 & 835 \\
\hline
\end{tabular}

Sumber: Data Primer Perusahaan

Tabel 2 Penjualan Kasur Busa Tahun 2018

\begin{tabular}{llrrrrr}
\hline Tahun & Bulan & Periode & Gold (unit) & Silver (unit) & Standar (unit) & Ekonomi (unit) \\
\hline & Januari & 1 & 66 & 192 & 11 & 1269 \\
& Februari & 2 & 45 & 60 & 5 & 1230 \\
Maret & 3 & 18 & 59 & 1 & 1248 \\
& April & 4 & 21 & 92 & 0 & 642 \\
& Mei & 5 & 62 & 143 & 11 & 925 \\
2018 & Juni & 6 & 55 & 35 & 2 & 1518 \\
& Juli & 7 & 68 & 67 & 0 & 1586 \\
& Agustus & 8 & 69 & 60 & 16 & 1151 \\
& September & 9 & 59 & 67 & 2 & 864 \\
& Oktober & 10 & 40 & 63 & 10 & 1045 \\
& November & 11 & 112 & 27 & 0 & 687 \\
Desember & 12 & 65 & 75 & 1 & 797 \\
\hline
\end{tabular}

Sumber: Data Primer Perusahaan

PT Buana Spring Foam memiliki tenaga kerja sebanyak 144 orang disemua bagian. Untuk bagian produksi kasur busa memiliki tenaga kerja sebanyak 23 orang, yang terdiri dari sebagai berikut: 
Tabel 3. Jumlah Tenaga Kerja

\begin{tabular}{clc}
\hline No. & \multicolumn{1}{c}{ Stasiun Kerja } & Jumlah Tenaga Kerja (Orang) \\
\hline 1 & Penimbangan & 6 \\
2 & Proses Foaming & 1 \\
3 & Pemotongan Vertikal & 2 \\
4 & Pemotongan Horizontal & 2 \\
5 & Penjahitan & 7 \\
6 & Pengemasan & 5 \\
\hline & Jumlah & 23 \\
\hline
\end{tabular}

Sumber: Data Primer Perusahaan

Pengaturan jam kerja pada PT Buana Spring Foam berlangsung selama tujuh jam kerja dan satu jam istirahat dalam enam hari (senin - sabtu) jadi selama satu bulan dapat dihitung sebanyak 24 hari. Apabila waktu kerja lebih dari tujuh jam, maka jam berikutnya akan terhitung sebagai jam lembur.

Data gaji per orang untuk kerja reguler sesuai dengan UMR daerah Banyumas, yaitu sebesar Rp 1.750.000. Sedangkan upah lembur sebesar Rp 55.800 yang didapat dari perhitungan sesuai dengan Undang-Undang No. 13 Tahun 2003 tentang Ketenagakerjaan pasal 78 ayat (2), (4), pasal 85 dan lebih lengkapnya diatur dalam Kepmenakertrans No. 102/MEN/VI/2004 mengenia Waktu dan Upah Kerja Lembur. Berdasarkan peraturan Kepmenakertrans No. 102/MEN/VI/2004, rumus perhitungan upah lembur adalah sebagai berikut:

$$
\begin{gathered}
\text { Jam Pertama }=1,5 \times 1 / 173 \times \text { upah sebulan } \\
\text { Jam Kedua dan Ketiga }=2 \times 1 / 173 \times \text { upah sebulan }
\end{gathered}
$$

Upah lembur:

Jam Pertama $=1,5 \times 1 / 173 \times 1750000=15200 / \mathrm{jam}$

Jam Kedua dan Ketiga $=2 \times 1 / 173 \times 1750000=20300 / \mathrm{jam}$

Total upah lembur karyawan:

Upah Lembur $=15200+20300+20300=55800 / \mathrm{jam}$

\section{Waktu Proses Produksi}

Proses pembuatan kasur busa yang dilakukan PT Buana Spring Foam memiliki beberapa mesin yang digunakan, adapun jenis mesin dan jumlahnya sebagai berikut:

Tabel 4 Jumlah Mesin Produksi

\begin{tabular}{clc}
\hline No & \multicolumn{1}{c}{ Mesin } & Jumlah Mesin (Unit) \\
\hline 1 & Timbangan & 2 \\
2 & Foaming & 1 \\
3 & Pemotong Vertikan & 1 \\
4 & Pemotong Horizontal & 1 \\
5 & Mesin Jahit & 6 \\
6 & Pengemasan & 2 \\
\hline \multicolumn{2}{c}{ Sumber: Data Primer Perusahaan }
\end{tabular}

Proses pembuatan pada kasur busa memiliki tiga tahap, yaitu persiapan, proses foaming, serta proses pemotongan dan pengemasan. Waktu proses pembuatan kasur busa dan stasiun kerja akan dijelaskan sebagai berikut: 
Tabel 5 Waktu Proses Produksi

\begin{tabular}{llrrrr}
\hline & \multicolumn{1}{c}{ Stasiun Kerja } & \multicolumn{4}{c}{ Jenis Produk } \\
\cline { 3 - 6 } No & $\begin{array}{c}\text { Gold } \\
\text { (Menit) }\end{array}$ & $\begin{array}{c}\text { Silver } \\
\text { (Menit) }\end{array}$ & $\begin{array}{c}\text { Standar } \\
\text { (Menit) }\end{array}$ & $\begin{array}{c}\text { Ekonomi } \\
\text { (Menit) }\end{array}$ \\
\hline 1 & Menimbang bahan baku dan & 40 & 30 & 25 & 25 \\
& membersihkan cetakan & & & & \\
2 & Proses foaming & 20 & 15 & 10 & 10 \\
3 & Pemindahan balokan busa & 0,5 & 0,5 & 0,5 & 0,5 \\
4 & Pemotongan vertical & 5 & 5 & 5 & 5 \\
5 & Pemotongan Horizontal & 5 & 5 & 5 & 5 \\
6 & Pendinginan & 4 & 1 & 1 & 1 \\
7 & Penjahitan dan penyarungan & 3 & 4 & 4 & 4 \\
8 & Pengemasan & 1 & 1 & 3 & 3 \\
9 & Pemeriksaan & & 3 & 1 & 1 \\
\hline & $\quad$ Jumlah & 79,5 & 64,5 & 54,5 & 54,5 \\
\hline
\end{tabular}

Sumber: Data Primer Perusahaan

Perhitungan konversi dilakukan pada data yang bersifat multi item, yang bertujuan agar produk tersebut memiliki satuan produksi yang sama, sebagai berikut:

$$
\begin{gathered}
D=\frac{\text { Waktu Proses tiap item }}{\text { Waktu proses item terbesar }} \\
\text { Tabel } 6 \text { Faktor Konversi }
\end{gathered}
$$

\begin{tabular}{crr}
\hline Jenis & Waktu Proses Total (Menit) & Faktor Konversi (Menit) \\
\hline Gold & 79,5 & 1 \\
Silver & 64,5 & 0,811320755 \\
Standar & 54,5 & 0,685534591 \\
Ekonomi & 54,5 & 0,685534591 \\
\hline
\end{tabular}

\section{Peramalan}

Sumber: Data Diolah

Taknik analisis data peramalan menggunakan dua metode pada setiap jenis produk. Pada jenis gold dan silver memiliki metode peramalan yang sama, yaitu metode trend dan metode pemulusan dengan musiman. Sedangkan jenis standar menggunakan metode moving average dan metode pemulusan, serta jenis ekonomi menggunakan metode moving average dengan musiman dan metode pemulusan dengan musiman. Hasil dari setiap metode adalah sebagai berikut:

\begin{tabular}{|c|c|c|c|c|c|c|c|c|c|}
\hline \multirow[b]{2}{*}{ Bulan } & \multirow[b]{2}{*}{ Periode } & \multicolumn{2}{|c|}{ Gold } & \multicolumn{2}{|c|}{ Silver } & \multicolumn{2}{|c|}{ Standar } & \multicolumn{2}{|c|}{ EKONOMI } \\
\hline & & $\begin{array}{l}\text { Metode } \\
\text { Trend }\end{array}$ & $\begin{array}{l}\text { Metode } \\
\text { Pemulusan } \\
\text { dengan } \\
\text { Musiman }\end{array}$ & $\begin{array}{l}\text { Metode } \\
\text { Trend }\end{array}$ & $\begin{array}{l}\text { Metode } \\
\text { Pemulusan } \\
\text { dengan } \\
\text { Musiman }\end{array}$ & $\begin{array}{l}\text { Metode } \\
\text { Moving } \\
\text { Average }\end{array}$ & $\begin{array}{l}\text { Metode } \\
\text { Pemulusan }\end{array}$ & $\begin{array}{l}\text { Metode } \\
\text { Moving } \\
\text { Average } \\
\text { dengan } \\
\text { Musiman } \\
\end{array}$ & $\begin{array}{l}\text { Metode } \\
\text { Pemulusan } \\
\text { dengan } \\
\text { Musiman }\end{array}$ \\
\hline Jan & 1 & 74 & 94 & 168 & 108 & 3 & 1 & 847 & 878 \\
\hline Feb & 2 & 78 & 59 & 171 & 51 & 3 & 1 & 771 & 798 \\
\hline Mar & 3 & 81 & 32 & 175 & 86 & 3 & 1 & 895 & 927 \\
\hline Apr & 4 & 84 & 42 & 178 & 69 & 3 & 1 & 760 & 787 \\
\hline Mei & 5 & 87 & 72 & 182 & 92 & 3 & 1 & 784 & 812 \\
\hline Jun & 6 & 91 & 68 & 186 & 54 & 3 & 1 & 1194 & 1236 \\
\hline Jul & 7 & 94 & 78 & 189 & 58 & 3 & 1 & 1371 & 1420 \\
\hline Agt & 8 & 97 & 83 & 193 & 48 & 3 & 1 & 1145 & 1185 \\
\hline Sep & 9 & 100 & 65 & 196 & 39 & 3 & 1 & 684 & 708 \\
\hline Okt & 10 & 104 & 64 & 200 & 54 & 3 & 1 & 651 & 674 \\
\hline Nov & 11 & 107 & 134 & 203 & 37 & 3 & 1 & 479 & 496 \\
\hline Des & 12 & 110 & 86 & 207 & 44 & 3 & 1 & 533 & 552 \\
\hline \multicolumn{2}{|c|}{ Total } & 1107 & 878 & 2248 & 741 & 39 & 14 & 10116 & 10475 \\
\hline
\end{tabular}

Table 7 Hasil Peramlan Produk Kasur Busa

Sumber: Data Diolah 
Tabel 8 Hasil Peramalan yang Ditentukan

\begin{tabular}{|c|c|c|c|c|c|c|}
\hline \multirow[b]{2}{*}{ Bulan } & \multirow[b]{2}{*}{ Periode } & Gold & Silver & Standar & Ekonomi & \multirow[b]{2}{*}{$\begin{array}{c}\text { Jumlah } \\
\text { (Unit) }\end{array}$} \\
\hline & & $\begin{array}{l}\text { Metode } \\
\text { Trend } \\
\text { (Unit) }\end{array}$ & $\begin{array}{c}\text { Metode Pemulusan } \\
\text { dengan Musiman } \\
\text { (Unit) }\end{array}$ & $\begin{array}{l}\text { Metode Moving } \\
\text { Average (Unit) }\end{array}$ & $\begin{array}{c}\text { Metode Pemulusan } \\
\text { dengan Musiman } \\
\text { (Unit) }\end{array}$ & \\
\hline Jan & 25 & 74 & 160 & 3 & 878 & 1115 \\
\hline $\mathrm{Feb}$ & 26 & 78 & 164 & 3 & 798 & 1043 \\
\hline Mar & 27 & 81 & 167 & 3 & 927 & 1178 \\
\hline Apr & 28 & 84 & 170 & 3 & 787 & 1044 \\
\hline Mei & 29 & 87 & 173 & 3 & 812 & 1075 \\
\hline Jun & 30 & 91 & 176 & 3 & 1236 & 1506 \\
\hline Jul & 31 & 94 & 180 & 3 & 1420 & 1697 \\
\hline Agt & 32 & 97 & 183 & 3 & 1185 & 1468 \\
\hline Sep & 33 & 100 & 186 & 3 & 708 & 997 \\
\hline Okt & 34 & 104 & 189 & 3 & 674 & 970 \\
\hline Nov & 35 & 107 & 193 & 3 & 496 & 799 \\
\hline Des & 36 & 110 & 196 & 3 & 552 & 861 \\
\hline Total & & 1107 & 2137 & 36 & 10473 & 13753 \\
\hline
\end{tabular}

Menetukan peramalan menggunakan tiga ukuran kesalahan historis, yaitu Mean Absolute Deviation (MAD), Mean Squared Error (MES), dan Mean Absolute Percent Error (MAPE). Data yang dihasilkan tertadapat pada Tabel 8. Adapun perhitungan matematisnya sebagai berikut:

$$
\begin{array}{r}
M A D=\frac{\sum \mid \text { Aktual }_{t}-\text { Ramalan }_{t} \mid}{n} \\
M S E=\frac{\left.\sum \text { Aktual }_{t}-\text { Ramalan }_{t}\right)^{2}}{n-1} \\
M A P E=\frac{\sum \frac{\mid \text { Aktual }_{t}-\text { Ramalan }_{t} \mid}{\text { Aktual }_{t}} \times 100}{n}
\end{array}
$$

\section{Rencana Kapasitas}

Kapasitas produksi untuk semua produk yang digunakan dalam perencanaan produksi ini diperoleh dari jumlah jam kerja setiap produk terhadap jumlah produk yang akan di produksi. Setelah memperoleh jumlah jam kerja, maka langkah selanjutnya adalah melakukan perhitungan kapasitas waktu yang dibutuhkan untuk setiap produk dengan cara:

$$
\begin{aligned}
& \text { Kapasitas Waktu yang Tersedia }=\frac{\text { Jam kerja } / \text { bulan } \times 60}{\text { Jumlah item }} \\
& \text { Kapasitas Waktu yang Tersedia }=\frac{168 \times 60}{4}=2520 \text { menit }
\end{aligned}
$$

Menentukan perhitungan kapasitas produksi setiap stasiun kerja per mesin untuk setiap item setip periode. Data yang digunakan adalah waktu yang tersedia, data waktu proses dalam Tabel 6, dan data kemampuan produksi dalam 15 balok busa, adapun datanya sebagai berikut:

Tabel 9 Jumlah Kasur Busa yang Dihasilkan Per 15 Balok

\begin{tabular}{ccc}
\hline $\begin{array}{c}\text { Jenis } \\
\text { Produk }\end{array}$ & $\begin{array}{c}\text { Jumlah Balok yang } \\
\text { Dihasilkan (Unit) }\end{array}$ & $\begin{array}{c}\text { Jumlah Unit yang } \\
\text { Dihasilkan (Unit) }\end{array}$ \\
\hline Gold & 2 & 8 \\
Silver & 4 & 16 \\
Standar & 1 & 4 \\
Ekonomi & 8 & 32 \\
\hline
\end{tabular}

Sumber: Data Primer Perusahaan

Perhitungan kapasitas mesin pada produksi kasur busa adalah sebagai berikut:

Tabel 10 Kapasitas Produksi yang Tersedia 
Analisis Perencanaan Kapasitas Produksi dengan Metode

\begin{tabular}{cccccc}
\hline \multirow{2}{*}{ Periode } & \multicolumn{5}{c}{ Jenis Produk } \\
\cline { 2 - 5 } & Gold (Unit) & Silver (Unit) & Standar (Unit) & Ekonomi (Unit) & \\
\hline 1 & 252 & 672 & 252 & 2016 & 3192 \\
2 & 252 & 672 & 252 & 2016 & 3192 \\
3 & 252 & 672 & 252 & 2016 & 3192 \\
4 & 252 & 672 & 252 & 2016 & 3192 \\
5 & 252 & 672 & 252 & 2016 & 3192 \\
6 & 252 & 672 & 252 & 2016 & 3192 \\
7 & 252 & 672 & 252 & 2016 & 3192 \\
8 & 252 & 672 & 252 & 2016 & 3192 \\
9 & 252 & 672 & 252 & 2016 & 3192 \\
10 & 252 & 672 & 252 & 2016 & 3192 \\
11 & 252 & 672 & 252 & 2016 & 3192 \\
12 & 252 & 672 & 252 & 2016 & 3192 \\
\hline
\end{tabular}

Sumber: Data Diolah

$$
\text { Kapasitas Mesin }=\frac{\text { Waktu yang tersedia } \times \text { Tenaga kerja }}{\text { Waktu proses } / \text { Jumlah unit }}
$$

Setelah diketahui kapasitas produksi setiap mesin untuk seluruh produk, maka kapasitas produksi yang tersedia adalah kapasitas mesin yang menghasilkan output terendah. Dari hasil perhitungan kapasitas mesin, output terendah untuk seluruh periode dan seluruh jenis produk yang dihasilkan oleh mesin Foaming. Oleh karena itu, data yang diambil pada setiap jenis adalah hasil dari perhitungan stasiun kerja foaming yang terdapat pada Tabel 10.

Dari hasil kapasitas yang tersedia maka akan dikonversi ke dalam standar waktu operasi setiap item. Data faktor konversi dapat dilihat pada Tabel 6

Kapasitas unit koversi $=$ kapasitas produksi $\times$ faktor konversi

Tabel 11 Kapasitas Tersedia setelah Dikonversi

\begin{tabular}{cccccc}
\hline \multirow{2}{*}{ Periode } & \multicolumn{5}{c}{ Jenis Produk } \\
\cline { 2 - 5 } & $\begin{array}{c}\text { Gold } \\
\text { (Unit) }\end{array}$ & $\begin{array}{c}\text { Silver } \\
\text { (Unit) }\end{array}$ & $\begin{array}{c}\text { Standar } \\
\text { (Unit) }\end{array}$ & $\begin{array}{c}\text { Ekonomi } \\
\text { (Unit) }\end{array}$ & $\begin{array}{c}\text { Kapasitas } \\
\text { (Unit) }\end{array}$ \\
\hline 1 & 252 & 545,208 & 172,755 & 1382,04 & 2352 \\
2 & 252 & 545,208 & 172,755 & 1382,04 & 2352 \\
3 & 252 & 545,208 & 172,755 & 1382,04 & 2352 \\
4 & 252 & 545,208 & 172,755 & 1382,04 & 2352 \\
5 & 252 & 545,208 & 172,755 & 1382,04 & 2352 \\
6 & 252 & 545,208 & 172,755 & 1382,04 & 2352 \\
7 & 252 & 545,208 & 172,755 & 1382,04 & 2352 \\
8 & 252 & 545,208 & 172,755 & 1382,04 & 2352 \\
9 & 252 & 545,208 & 172,755 & 1382,04 & 2352 \\
10 & 252 & 545,208 & 172,755 & 1382,04 & 2352 \\
11 & 252 & 545,208 & 172,755 & 1382,04 & 2352 \\
12 & 252 & 545,208 & 172,755 & 1382,04 & 2352 \\
\hline
\end{tabular}

Sumber: Data Diolah

\section{Perencanaan Agregat}

Untuk menghitung perencanaan agregat, maka akan dibutuhkan data yang didapat dari perusahaan sebagai beriku: gaji karyawan sebesar Rp 1.750.000/tahun, upah lembur sebesar Rp 55.800 /hari, biaya penyimpanan sebesar Rp 350.000 /bulan, persediaan awal sebesar 1230 unit tenaga kerja sebanyak 23 orang. 


\begin{tabular}{lrr}
\hline \multicolumn{1}{c}{ Nama } & \multicolumn{1}{c}{ Biaya (Rp) } & Biaya Per Unit (Rp) \\
\hline Gaji Pegawai & 1750000 & 745 \\
Upah Lembur & 55800 & 850 \\
Biaya Penyimpanan & 350000 & 149 \\
\hline Sumber: Data Diolah & &
\end{tabular}

Perhitungan perencanaan agregat ini akan menggunkan dua metode yang akan dibahas sebagi berikut:

Metode Tenaga Kerja Tetap

Perrhitungan untuk total supply adalah:

Total Supply $=$ Reguler + Lembur

Total Supply $=2352+0=2352$

Tabel 13 Perencanaan Agregat

\begin{tabular}{ccrrrrr}
\hline $\begin{array}{c}\text { Perio } \\
\text { de }\end{array}$ & $\begin{array}{c}\text { Hari Kerja } \\
\text { (Hari) }\end{array}$ & $\begin{array}{c}\text { Permintaan } \\
\text { (Unit) }\end{array}$ & $\begin{array}{c}\text { Reguler } \\
\text { (Unit) }\end{array}$ & $\begin{array}{c}\text { Lembur } \\
\text { (Unit) }\end{array}$ & $\begin{array}{c}\text { Total Supply } \\
\text { (Unit) }\end{array}$ & $\begin{array}{c}\text { Inventory Akhir } \\
\text { (Unit) }\end{array}$ \\
\hline 1 & 24 & 1115 & 2352 & 0 & 2352 & 2467 \\
2 & 24 & 1043 & 2352 & 0 & 2352 & 1309 \\
3 & 24 & 1178 & 2352 & 0 & 2352 & 1174 \\
4 & 24 & 1044 & 2352 & 0 & 2352 & 1308 \\
5 & 24 & 1075 & 2352 & 0 & 2352 & 1277 \\
6 & 24 & 1506 & 2352 & 0 & 2352 & 846 \\
7 & 24 & 1697 & 2352 & 0 & 2352 & 655 \\
8 & 24 & 1468 & 2352 & 0 & 2352 & 884 \\
9 & 24 & 997 & 2352 & 0 & 2352 & 1355 \\
10 & 24 & 970 & 2352 & 0 & 2352 & 1382 \\
11 & 24 & 799 & 2352 & 0 & 2352 & 1553 \\
12 & 24 & 861 & 2352 & 0 & 2352 & 1491 \\
\hline Jumla & 288 & 13753 & 28224 & 0 & 28224 & 15701 \\
h & 24 & & & &
\end{tabular}

Tabel 14 Total Biaya Metode Tenaga Kerja Tetap

\begin{tabular}{crrr}
\hline Nama & Biaya (Rp) & Jumlah (Rp) & Jumlah Biaya (Rp) \\
\hline Reguler & 745 & 28224 & 21026880 \\
Lembur & 850 & 0 & 0 \\
Persediaan & 149 & 15701 & 2339449 \\
\hline \multicolumn{4}{c}{ Total Biaya } \\
\hline
\end{tabular}

Sumber: Data Diolah 
Metode Transportasi

Tabel 15 Perencanaan Agregat

\begin{tabular}{cccrrr}
\hline $\begin{array}{c}\text { Period } \\
\mathrm{e}\end{array}$ & $\begin{array}{c}\text { Permintaan } \\
\text { (Unit) }\end{array}$ & $\begin{array}{c}\text { Reguler } \\
\text { (Unit) }\end{array}$ & $\begin{array}{c}\text { Lembur } \\
\text { (Unit) }\end{array}$ & $\begin{array}{c}\text { Total Supply } \\
\text { (Unit) }\end{array}$ & $\begin{array}{c}\text { Inventory Akhir } \\
\text { (Unit) }\end{array}$ \\
\hline 1 & 1115 & 2353 & 0 & 2353 & 2468 \\
2 & 1043 & 2353 & 0 & 2353 & 1309 \\
3 & 1178 & 2353 & 0 & 2353 & 1175 \\
4 & 1044 & 2353 & 0 & 2353 & 1309 \\
5 & 1075 & 2353 & 0 & 2353 & 1278 \\
6 & 1506 & 2353 & 0 & 2353 & 847 \\
7 & 1697 & 2353 & 0 & 2353 & 656 \\
8 & 1468 & 2353 & 0 & 2353 & 885 \\
9 & 997 & 2353 & 0 & 2353 & 1356 \\
10 & 970 & 2353 & 0 & 2353 & 1383 \\
11 & 799 & 2353 & 0 & 2353 & 1554 \\
12 & 861 & 2353 & 0 & 2353 & 1492 \\
\hline Jumlah & 13753 & 28236 & 0 & 28236 & 15701 \\
\hline \multicolumn{7}{c}{ Sumber: Data Diolah } & & & &
\end{tabular}

Perhitungan untuk total supply adalah:

Total Supply $=$ Reguler + Lembur

Total Supply $=2352+0=2352$

Tabel 16 Hasil Perhitungan Biaya Metode Transportasi

\begin{tabular}{crrr}
\hline Nama & \multicolumn{1}{c}{ Biaya } & \multicolumn{1}{c}{ Jumlah } & Jumlah Biaya \\
\hline Reguler & 745 & 28224 & 21026880 \\
Lembur & 850 & 0 & 0 \\
Penyimpanan & 149 & 15701 & 2339449 \\
\hline \multicolumn{4}{c}{ Total Biaya } \\
\end{tabular}

Sumber: Data Diolah

\begin{tabular}{|c|c|c|c|c|c|c|c|c|c|c|c|c|c|c|}
\hline $\begin{array}{l}\text { Optiral cost = } \\
92: 43770\end{array}$ & Perod 1 & Pariod 2 & Perict3 & Period 4 & Period5 & Perid 6 & Period 7 & Peridd 8 & Perod: & Period 10 & Perod il & Perod 12 & $\begin{array}{r}\text { Eucess } \\
\text { Capecty }\end{array}$ & Capacty \\
\hline ritheaby & 1115 & 115 & & & & & & & & & & & & 1230 \\
\hline Period 1 Aegitre & & & & & & & & & & & & & 2252 & 2552 \\
\hline Period 2 PegiTre & & 988 & & & & & & & & & & & 1424 & 2552 \\
\hline Perid 3 AagTire & & & 1178 & & & & & & & & & & 1174 & 2252 \\
\hline Period 4 Aagitre & & & & 104 & & & & & & & & & 130 & 2552 \\
\hline Perid5 Aegitre & & & & & 1075 & & & & & & & & 1277 & 2552 \\
\hline Period 6 Aagitre & & & & & & $15 \%$ & & & & & & & 84: & 2552 \\
\hline Period 7 Aagire & & & & & & & 1697 & & & & & & 655 & 2552 \\
\hline Perid B Aagitre & & & & & & & & 1488 & & & & & 804 & 2252 \\
\hline Period 9 Aagire & & & & & & & & & 997 & & & & 1355 & 2252 \\
\hline Period 1I AlggTre & & & & & & & & & & 970 & & & 1302 & 2252 \\
\hline Perid 11 iegine & & & & & & & & & & & 799 & & 1553 & 2352 \\
\hline Perid 12 Pegitre & & & & & & & & & & & & 881 & 1451 & 2552 \\
\hline Denterd & 1115 & 1043 & 1178 & 104 & 1075 & 1506 & 1607 & 1488 & 997 & 970 & 739 & 851 & 15711 & \\
\hline
\end{tabular}

Sumber: Data Perhitungan dari Software POM-QM for Windows

Gambar 1. Perencanaan Agregat dengan Tabel Transportasi

\section{Proses Disagregasi}

Pada tahap perhitungan ini akan mencari presentase untuk setiap jenis kasur busa dengan Metode Cut \& Fit, berukut adalah cara perhitungannya:

Perhitungan Presentase Permintaan Produk 
Perhitungan Produksi Setiap Jenis

$$
\text { Item } n 1 \%=\frac{\sum \text { peramalan } n 1}{\sum \text { demand }} \times 100 \%
$$

\begin{tabular}{|c|c|}
\hline Jenis Kasur Busa & Presentase \\
\hline Gold & $8,1 \%$ \\
\hline Silver & $15,45 \%$ \\
\hline Standar & $0,26 \%$ \\
\hline Ekonomi & $76,15 \%$ \\
\hline
\end{tabular}

Sumber: Data Diolah

Tabel 18 Produk Kasur Busa Satuan Agregat

\begin{tabular}{lccccc}
\hline \multicolumn{1}{c}{ Bulan } & Periode & Gold (Unit) & Silver (Unit) & Standar (Unit) & Ekonomi (Unit) \\
\hline Januari & 1 & 90 & 173 & 3 & 849 \\
Februari & 2 & 84 & 162 & 3 & 794 \\
Maret & 3 & 95 & 183 & 3 & 897 \\
April & 4 & 84 & 162 & 3 & 795 \\
Mei & 5 & 87 & 167 & 3 & 819 \\
Juni & 6 & 121 & 234 & 4 & 1147 \\
Juli & 7 & 137 & 264 & 4 & 1292 \\
Agustus & 8 & 118 & 228 & 4 & 1118 \\
September & 9 & 80 & 155 & 3 & 759 \\
Oktober & 10 & 78 & 151 & 3 & 739 \\
November & 11 & 64 & 124 & 2 & 608 \\
Desember & 12 & 69 & 134 & 2 & 656 \\
\hline \multicolumn{2}{c}{ Jumlah } & 1107 & 2137 & 36 & 10473 \\
\hline \multicolumn{2}{c}{ Sumber: Data Diolah } & \multicolumn{5}{c}{}
\end{tabular}

\section{Jadwal Induk Produksi}

Untuk menghitung JIP yang dikoversi, maka faktor konversi akan diambil dari Tabel 6 Data pembagian disagregasi dengan faktor konversi adalah sebagai berikut:

$$
\text { Item }=\frac{\text { Hasil Disagregasi per Jenis }}{\text { Faktor Konversi }}
$$

\begin{tabular}{|c|c|c|c|c|c|c|}
\hline \multirow{2}{*}{ Bulan } & \multirow{2}{*}{ Periode } & \multicolumn{4}{|c|}{ Jenis Produk } & \multirow{2}{*}{ Jumlah (Unit) } \\
\hline & & Gold (Unit) & Silver (Unit) & Standar (Unit) & Ekonomi (Unit) & \\
\hline Januari & 1 & 90 & 214 & 4 & 1239 & 1546 \\
\hline Februari & 2 & 84 & 200 & 4 & 1159 & 1446 \\
\hline Maret & 3 & 95 & 226 & 4 & 1309 & 1633 \\
\hline April & 4 & 84 & 200 & 4 & 1160 & 1448 \\
\hline Mei & 5 & 87 & 206 & 4 & 1194 & 1491 \\
\hline Juni & 6 & 121 & 288 & 6 & 1673 & 2088 \\
\hline Juli & 7 & 137 & 325 & 6 & 1885 & 2353 \\
\hline Agustus & 8 & 118 & 281 & 6 & 1631 & 2036 \\
\hline September & 9 & 80 & 191 & 4 & 1107 & 1382 \\
\hline Oktober & 10 & 78 & 186 & 4 & 1077 & 1345 \\
\hline November & 11 & 64 & 153 & 3 & 888 & 1108 \\
\hline Desember & 12 & 69 & 165 & 3 & 956 & 1194 \\
\hline \multicolumn{2}{|c|}{ Total } & 1107 & 2634 & 53 & 15277 & 19071 \\
\hline
\end{tabular}

Tabel 19 Hasil Jadwal Induk Produksi yang Dikonversi

\section{Rought Cut Capacity Planning}


Tabel 20 Hasil Bill of Capacity

\begin{tabular}{lrrrr}
\hline \multirow{2}{*}{ Stasiun Kerja } & \multicolumn{4}{c}{ Standar Hours (Jam) } \\
\cline { 2 - 5 } & \multicolumn{1}{c}{ Gold } & \multicolumn{1}{c}{ Silver } & \multicolumn{1}{c}{ Standar } & \multicolumn{1}{c}{ Ekonomi } \\
\hline Menimbang & 0,6666667 & 0,5 & 0,416666667 & 0,416666667 \\
Foaming & 0,4166667 & 0,3333333 & 0,25 & 0,25 \\
Pemotongan V & 0,0916667 & 0,0916667 & 0,091666667 & 0,091666667 \\
Pemotongan H & 0,0916667 & 0,0916667 & 0,091666667 & 0,091666667 \\
Menjahit & 0,0708333 & 0,0708333 & 0,070833333 & 0,070833333 \\
Pengemasan & 0,05 & 0,05 & 0,05 & 0,05 \\
\hline
\end{tabular}

Sumber: Data Diolah

Untuk menentukan perhitungan RCCP, maka akan dibutuhkan data peramalan yang terdapat pada Tabel 8, data Jadwal Induk Produksi yang terdapat pada Tabel 19 dan data kapasitas tersedia yang terdapat pada Tabel 11. Selanjutkan akan mencari data Standar hours yang menghasilkan data Bill of Capacity, adapun perhitungannya sebagai berikut:

$$
\text { Standar Hours }=\frac{\text { Run Time }+\left(\frac{\text { Setup }}{\text { Lot size }}\right)}{60}
$$

Hasil kapasitas terpakai didapat dari perhitungan Jadwal Induk Produski dengan standar hours, adapun perhitungannya sebagai berikut:

Item $=$ Jadwal Induk Produksi $\times$ Standar Hours

Tabel 21 Kapasitas Terpakai Produk Kasur Busa

\begin{tabular}{lccrrr}
\hline \multirow{2}{*}{ Bulan } & \multirow{2}{*}{ Periode } & \multicolumn{4}{c}{ Jenis Produk } \\
\cline { 3 - 6 } & & Gold (Unit) & Silver (Unit) & Standar (Unit) & Ekonomi (Unit) \\
\hline Januari & 1 & 124,525426 & 242,90741 & 4,1332838 & 1202,4412 \\
Februari & 2 & 116,484323 & 227,22191 & 3,8663812 & 1124,7947 \\
Maret & 3 & 131,561392 & 256,63222 & 4,3668237 & 1270,3818 \\
April & 4 & 116,596005 & 227,43976 & 3,8700882 & 1125,8732 \\
Mei & 5 & 120,058146 & 234,19324 & 3,9850046 & 1159,3043 \\
Juni & 6 & 168,193087 & 328,0884 & 5,5827134 & 1624,1044 \\
Juli & 7 & 189,524348 & 369,69854 & 6,2907468 & 1830,0831 \\
Agustus & 8 & 163,949171 & 319,80994 & 5,4418482 & 1583,1243 \\
September & 9 & 111,346951 & 217,20062 & 3,6958601 & 1075,1873 \\
Oktober & 10 & 108,331537 & 211,31856 & 3,5957716 & 1046,0699 \\
November & 11 & 89,2339153 & 174,06549 & 2,9618778 & 861,65963 \\
Desember & 12 & 96,1581991 & 187,57245 & 3,1917107 & 928,52183 \\
\hline
\end{tabular}

Sumber: Data Diolah

Load Profile disefinisikan sebagai tampilan dari kebutuhan kapasitas di waktu mendatang berdasarkan pesanan-pesanan yang direncanakan dan dikeluarkan sepanjang periode waktu tertentu. Validasi RCCP dikatakan layak apabila kapasitas yang dibutukan dapat dipenuhi oleh kapasitas tersedia. Adapun perbandingannya sebagai berikut: 
Tabel 27 Kapasitas Terpakai dan Kapasitas Tersedia

\begin{tabular}{ccc}
\hline Periode & Kapasitas Terpakai (Unit) & Kapasitas Tersedia (Unit) \\
\hline 1 & 1574 & 2352 \\
2 & 1472 & 2352 \\
3 & 1663 & 2352 \\
4 & 1474 & 2352 \\
5 & 1518 & 2352 \\
6 & 2126 & 2352 \\
7 & 2396 & 2352 \\
8 & 2072 & 2352 \\
9 & 1407 & 2352 \\
10 & 1369 & 2352 \\
11 & 1128 & 2352 \\
12 & 1215 & 2352
\end{tabular}

Sumber: Data Diolah

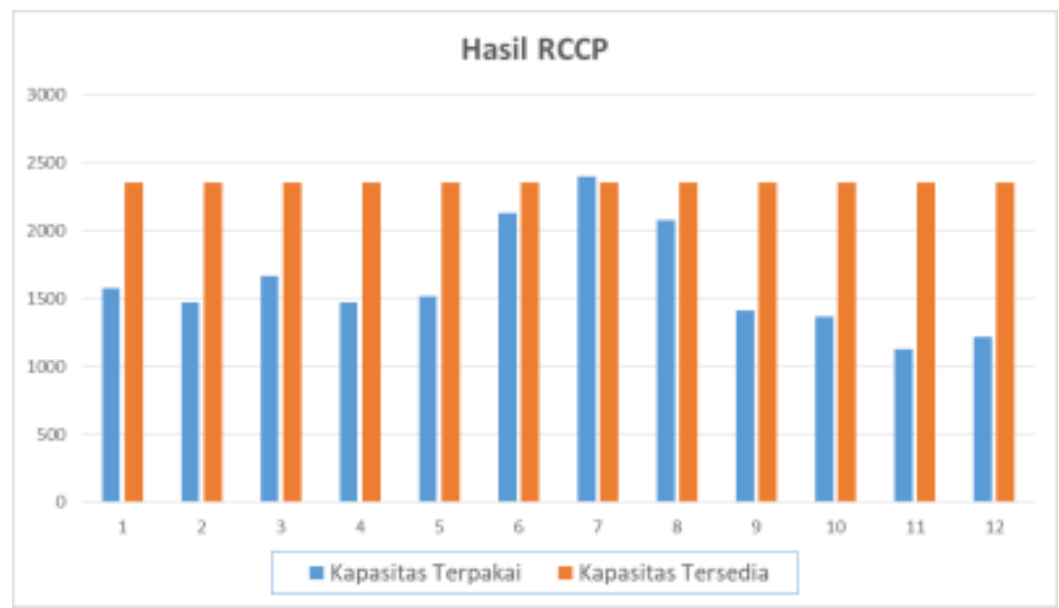

Sumber: Data Diolah

Gambar 1 Hasil Perbandingan Kapasitas Terpakai dengan Kapasitas Tersedia

Bedasarkan hasil perhitungan dari load profile menunjukkan bahwa hasil penelitian terhadap jadwal induk produksi layak digunakan untuk proses produksi kasur busa. Kelayakan ini dihitung berdasarkan kesesuaian antara total kapasitas tersedia sebanayak 28224 unit dengan total kapasitas terpakai sebanyak 19415 unit. Oleh karena itu kapasitas tersedia dapat memenuhi kapasitas terpakai

\section{SIMPULAN DAN IMPLIKASI}

\section{Simpulan}

Metode peramalan yang dipilih adalah metode trend untuk gold, metode pemulusan dengan musiman untuk silver, metode moving average untuk standar, dan metode pemulusan dengan musiman untuk ekonomi. Hasil dari peramalan untuk dua tahun sebelumnya mengalami penurunan, sehingga pada peramalan untuk masa yang akan datang mengalami hal sama. Hal ini diduga karena penjualan menurun akibat tidak stabilnya harga bahan baku akibat kurs dollar yang meningkat. Kenaikan harga bahan baku ini berdampak pada harga jual semakin tinggi dan bidang pemasaran mengalami kesulitan untuk memasarkan produknya.

Perencanaan agregat yang digunakan untuk melakukan proses produksi secara menyeluruh dilakuakan dengan metode tenaga kerja tetap dan metode transportasi. Dari hasil perhitungan kedua metode tersebut mendapatkan hasil yang sama, yaitu sebesar Rp 23.366.329. Penyusunan Jadwal Induk Produksi dilakukan dengan disagregasi hasil perencanaan agregat menggunakan metode cut \& fit. 
Tujuan dari disagregasi ini adalah untuk mengetahui besarnya presentase setiap jenis kasur busa. Kemudian hasil dari Jadwal Induk Produksi dikonversikan sesuai dengan faktor konversi yang telah ditetapkan.

Atas dasar hasil Jadwal Induk Produksi, maka dapat ditentukan kapasitas kasar (RCCP) untuk menyesuaikan Jadwal Induk Produksi dengan kapasitas produk yang tersedia. Rought Cut Capacity Planning merupakan metode untuk membandingkan hasil Jadwal Induk Produksi dengan kapasitas yang dimiliki perusahaan. Metode yang digunakan untuk menganalisis Jadwal Induk Produksi adalah Bill of Labour. Hasil Rought Cut Capacity Planning menunjukan bahwa kapasitas produksi dapat memenuhi kebutuhan produksi yang direncanakan untuk periode mendatang.

\section{Implikasi}

Diharapkan PT Buana Spring Foam melakukan prediksi terhadap permintaan produk menggunakan metode peramalan yang sesuai dengan pola data permintaan. Sehingga perusahaan dapat mengetahui jumlah barang yang harus diproduksi dan dapat memenuhi permintaan konsumen.

Perusahaan dapat menambah kerja sama dengan daerah diluar dari daerah penjualan yang sekarang, sehingga perusahaan dapat menambah daerah penjualan dan tidak mengalami penumpukan pada gudang dan tidak melakukan slow moving.

\section{DAFTAR PUSTAKA}

Chatras, Clement, dkk. 2015. High variety impacts on Master Production Schedule: a case study from the automotive industry. IFAC-PapersOnLine 48-2, Pages 1073-1078.

Cherkaoui, Kaouthar, dkk. 2015 A Time Driven RCCP Model with Two Levels of Planning and a Reactive Planning Approach for Tactical Project Planning. Procedia Computer Science Vol. 64, Pages 257 264.

Erni, Nofi dan Rafrianti, Santi. 2007. Usulan Rencana Kapasitas Produksi Menggunakan Metode RCCP dan Pendekatan Sistem Dinamis Pada PT Dellifood Sentosa Corpindo-Tangerang. Jurnal Inovisi Vol. 6, No.2, Hal. 141.

Gaspersz, Vincent. 1998. Production Planning and Inventory Control. Gramedia Pustaka Utama. Jakarta.

Harini. 2014. Peningkatan Kapasitas Produksi Peti Alumunium Untuk Memenuhi Kebutuhan Permintaan Melalui Optimalisasi Jadwal Induk Produkasi di PT BJK. Jurnal Ilmiah WIDYA Vol. 2, No. 3, Hal. 37-41.

Heizer, Jay dan Render, Barry. 2016. Manajemen Operasi Manajemen Keberlangsungan dan Rantai Pasokan. Salemba Empat. Jakarta.

Iasya, Adel dan Handayani, Yuanita. 2015. Material Requirement Planning Analysis In Micro, Small and Medium Enterprise. Journal of Business and Management Vol. 4. No. 3, Hal. 317-329.

Iksan. 2010. Analisis Perencanaan Kapasitas Produksi Pada PT Muncul Abadi dengan Metode Rough Cut Capacity Planning. Jurnal Matrik Vol. VIII, No. 2, Hal. 91-99.

Jonsson, Patrik and Ivert, Linea Kjellsdotter. 2015. Improving performance with sophisticated Master Production Scheduling. Int. J. Production Economics Vol. 168, Pages 118-130.

Kusuma, Hendra. 2009. Manajemen Produksi Perencanaan dan Pengendalian Produksi. CV Andi Offset. Yogyakarta.

Nurcahyo, Yusuf Eko. 2015. Perencanaan Jadwal Induk Produksi dengan Menggunakan Linier Progremming Pada Industri Manufaktur PT "X". Jurnal Teknik Industri HEURISTIC Vol. 12, No. 2, Hal. 117-123.

Rasbina, Atanisa. Sinulingga, Sukaria. dan Siregar, Ikhsan. 2013. Perencanaan Jadwal Induk Produksi Pada PT XYZ. e-Jurnal Teknik Industri FT USU Vol. 2, No. 1, Hal. 54-57. 
Risal, Wawan K, Puryani, dan Nursubiyantoro, Eko. 2017. Perencanaan Kebutuhan Kapasitas Produksi Pada SP Alumunium. Jurnal OPSI Vol. 10, No. 1, Hal. 11-18.

Sanjaya, Rosi Leo. Munir, Misbach. dan Bashori, Hasan. 2016. Penerapan Metode Dynamic Programming Untuk Perencanaan Jadwal Induk Produksi (JIP) di PT XYZ. Journal Knowlage Industrial Engineering (JKIE) Vol. 3, No. 2, Hal. 40-50.

Sidiq, Muhammad Nasir dan Sutoni, Akhmad. 2017. Perencanaan dan Penentuan Jadwal Induk Produksi di PT Arwina Triguna Sejahtera. Jurnal Media Teknik \& sistem Industri Vol. 1, Hal 11-25.

Sinulingga, Sukaria. 2009. Perencanaan dan Pengendalian Produksi. Graha Ilmu. Yogyakarta.

Stevenson, Willian J. dan Chuong, Sum Chee. 2014. Manajemen Operasi Perspektif Asia Edisi 9 Buku 2. Salemba Empat. Jakarta.

Wardhani, Arie Restu. 2010. Perencanaan Agregat dengan Metode Transportasi Pada PT X Pasuruan. Widya Teknika Vol. 18, No. 1, Hal. 6-10. 